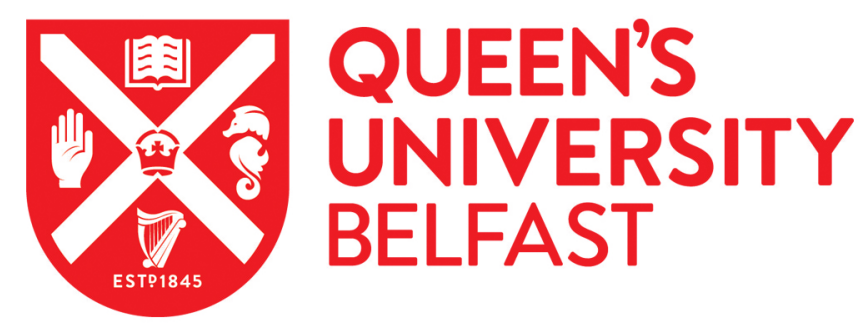

\title{
Mode I interlaminar fracture toughness of thin-ply laminates with CNT webs at the crack interface
}

Di Leonardo, S., Nistal, A., Catalanotti, G., Hawkins, S. C., \& Falzon, B. G. (2019). Mode I interlaminar fracture toughness of thin-ply laminates with CNT webs at the crack interface. Composite Structures, 225, [111178]. https://doi.org/10.1016/j.compstruct.2019.111178

\section{Published in:}

Composite Structures

\section{Document Version:}

Peer reviewed version

\section{Queen's University Belfast - Research Portal:}

Link to publication record in Queen's University Belfast Research Portal

\section{Publisher rights}

Copyright 2019 Elsevier.

This manuscript is distributed under a Creative Commons Attribution-NonCommercial-NoDerivs License

(https://creativecommons.org/licenses/by-nc-nd/4.0/), which permits distribution and reproduction for non-commercial purposes, provided the author and source are cited

\section{General rights}

Copyright for the publications made accessible via the Queen's University Belfast Research Portal is retained by the author(s) and / or other copyright owners and it is a condition of accessing these publications that users recognise and abide by the legal requirements associated with these rights.

Take down policy

The Research Portal is Queen's institutional repository that provides access to Queen's research output. Every effort has been made to ensure that content in the Research Portal does not infringe any person's rights, or applicable UK laws. If you discover content in the Research Portal that you believe breaches copyright or violates any law, please contact openaccess@qub.ac.uk. 


\section{Accepted Manuscript}

Mode I interlaminar fracture toughness of thin-ply laminates with CNT webs at the crack interface

Sofia Di Leonardo, Andrés Nistal, Giuseppe Catalanotti, Stephen C. Hawkins, Brian G. Falzon

PII: S0263-8223(18)34582-3

DOI: https://doi.org/10.1016/j.compstruct.2019.111178

Article Number: $\quad 111178$

Reference: $\quad$ COST 111178

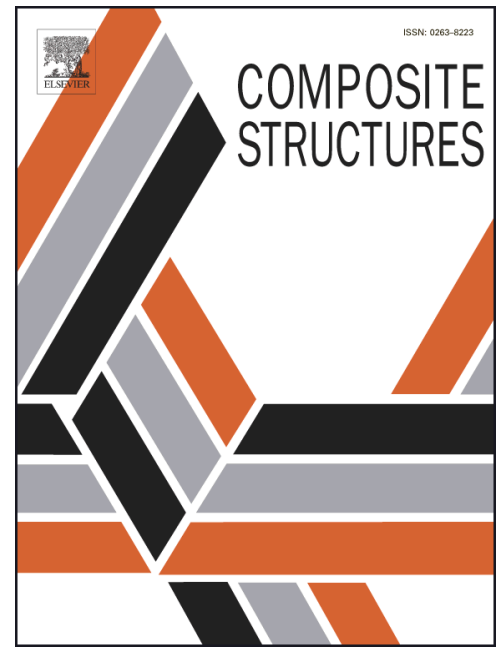

To appear in:

Composite Structures

Received Date: $\quad 18$ December 2018

Revised Date: $\quad 10$ April 2019

Accepted Date: $\quad 18$ June 2019

Please cite this article as: Di Leonardo, S., Nistal, A., Catalanotti, G., Hawkins, S.C., Falzon, B.G., Mode I interlaminar fracture toughness of thin-ply laminates with CNT webs at the crack interface, Composite Structures (2019), doi: https://doi.org/10.1016/j.compstruct.2019.111178

This is a PDF file of an unedited manuscript that has been accepted for publication. As a service to our customers we are providing this early version of the manuscript. The manuscript will undergo copyediting, typesetting, and review of the resulting proof before it is published in its final form. Please note that during the production process errors may be discovered which could affect the content, and all legal disclaimers that apply to the journal pertain. 


\title{
Mode I interlaminar fracture toughness of thin-ply laminates with CNT webs at the crack interface
}

\author{
Sofia Di Leonardo ${ }^{\mathrm{a}}$, Andrés Nistal ${ }^{\mathrm{b}}$, Giuseppe Catalanotti ${ }^{\mathrm{a},{ }^{*},}$, Stephen C. Hawkins ${ }^{\mathrm{a}, \mathrm{c}}$, Brian G. Falzon ${ }^{\mathrm{a}, \uparrow}$ \\ ${ }^{a}$ Advanced Composites Research Group (ACRG), School of Mechanical and Aerospace Engineering, Queen's University Belfast, Belfast
} BT9 5 AH, UK

${ }^{b}$ Institute for Materials Discovery, University College London, Roberts Building, London WC1E 7JE, UK

${ }^{c}$ Department of Materials Science and Engineering, Monash University, Clayton, Victoria 3800, Australia

\begin{abstract}
Pristine and functionalized carbon nanotube (CNT) webs were introduced at the interlaminar region of two different thin-ply carbon fibre reinforced polymer systems (NTPT 402 prepreg, and TeXtreme/SE84LV). The Mode I interlaminar fracture toughness (ILFT) for the NTPT 402 material was substantially lower. In contrast when SE84LV resin was used, the resistance curves were virtually unchanged and with no depreciation in the steady state value of the ILFT. This demonstrates that a careful choice of the resin is essential to permit the embedding of CNT webs in thin-ply laminates without compromising structural performance and opens a new way towards the development of multifunctional thin-ply structures.
\end{abstract}

Keywords: A. Thin-ply laminates; B. Carbon nanotube (CNT) webs; C. Interlaminar fracture toughness

\section{Introduction}

Carbon nanotube (CNT) webs have recently been proposed as a promising route to achieving multifunctional carbon fibre reinforced polymer (CFRP) laminates [1-3]. The highly conductive CNT webs are drawn directly from specially grown CNT forests produced by chemical vapour deposition (CVD) [4]. The webs can be interleaved with plies of carbon fibre $(\mathrm{CF})$ to tune the thermal and electrical properties of the laminate with negligible weight penalty.

Despite their negligible weight and thickness, the introduction of CNT webs may affect the interlaminar fracture toughness (ILFT) behaviour. In standardised mode I ILFT tests (ASTM D5528 [5]), using a double cantilever beam (DCB) made from unidirectional composite plies, webs may hinder the nesting between the carbon fibres of different plies, reducing the bridging effect and consequently the steady-state ILFT. Moreover, it has been observed that the interaction of CNTs with some epoxy resins has a major influence on ILFT. Bhanushali and Bradford [6], working with woven glass fibre reinforced polymer (GFRP) composites, found that ILFT was either marginally degraded or enhanced, depending on the orientation and number of layers of the CNT webs.

Chitwan et al. [7] observed a substantial reduction (- 65\%) of the mode I ILFT when using CNT webs with Solvay 977-2 epoxy resin composite system while a small increase was observed with the Gurit SE84LV resin. Care,

\footnotetext{
* Corresponding author. Tel.: +44 (0)28 90974502.

E-mail address: g.catalanotti@qub.ac.uk

$\dagger$ Corresponding author. Tel.: +44 (0)28 90975640.

E-mail address: b.falzon@qub.ac.uk
} 
therefore, needs to be taken when selecting the resin, because the reduction of the fracture toughness can be considerable and unacceptable for structural applications.

Nistal et al $[8,9]$ demonstrated a way of improving the interaction between the resin and CNT web without affecting the orientation or the microstructure of the CNTs, important in underpinning the development of CNT web-based multifunctionality. This was achieved through a single step gas-phase amino functionalisation which enhanced ILFT of conventional SE84LV CFRP by $24 \%$ with respect to pristine CNT webs.

These preliminary investigations [6,7] have considered the use of CNT webs in conventional composite laminates. However it is important to study how the use of CNT webs may affect the ILFT of thin-ply laminates because, by combining these two non-conventional reinforcements, new opportunities may arise, and risks identified, in the development of multifunctional composite structures [10].

Conventional composite laminates have a ply thickness typically between 100 and $200 \mu \mathrm{m}$, while thin-ply can be as low as $15 \mu \mathrm{m}$. The reduction of the ply thickness results in the suppression of all subcritical damage mechanisms associated with the matrix, such as matrix cracking and delamination [11-14]. Although a reduced ply thickness may also result in a reduction in ILFT [15] (due to a reduction of the bridging effect caused by less waviness of the fibre in a thin ply), it renders the laminate less prone to both matrix cracking induced delamination (MCID) and free edge delamination (FED) [16]. This is because the lower ply thickness causes a lower interlaminar stress concentration at the adjacent interface, delaying the premature matrix cracking and delamination.

A combination of the conventional CF ply, thin CF ply and CNT web in an epoxy matrix offers the potential to create a truly hierarchical composite structure which optimises the advantages of each component, introduces additional through-thickness characteristics such as thermal and electrical conductivity and mitigates any weaknesses [13]. Such flexibility also underpins the development of additional functionalities such as structural health monitoring, anti-icing/de-icing and lightning strike protection within the composite structure [10].

We now report a study of the ILFT when CNT webs are combined with thin-ply CFRP and on progress towards the development of practical multifunctional hierarchical systems. Two different thin-ply materials (a UD prepreg and UD dry fibre), and both pristine and amino-functionalized CNT webs are utilized to explore the effect of resinCNT interaction and sample fabrication.

\section{Materials and methods}

\subsection{Materials}

Two thin-ply material systems were used in this work: i) NTPT 402, a UD prepreg (MR70 CF) of 300 mm width provided by North Thin Ply Technology, with a nominal thickness of $15 \mu \mathrm{m}$, a CF areal weight of 15 gsm, and a resin content of 38\%wt; and ii) UTS50S UD, a 'spread-tow-tape' of dry carbon fibre carried on a backing strip, supplied by TeXtreme, with a CF areal weight of $32 \mathrm{gsm}$ and a width of $25 \mathrm{~mm}$. Thin plies and CNT webs were only introduced in the middle plane of the laminate (crack plane), while for the outer parts the Gurit HMC SE84LV unidirectional prepreg, with a nominal thickness of $0.35 \mathrm{~mm}$, was used. This also provided the resin to infuse the dry TeXtreme ply and included CNT web, whereas the NTPT 402 prepreg product provided the resin to infuse the CNT web included in those samples. 
Directly spinnable CNTs were produced by a CVD process as reported elsewhere [15]. Highly aligned CNT forests were grown on a silicon wafer bearing a catalytic iron layer. Using a gas mixture of acetylene and hydrogen diluted in helium, a temperature of $690{ }^{\circ} \mathrm{C}$ and a dwell time of only 12 minutes, $300 \mu \mathrm{m}$ long CNTs with an average of 6 walls and $10 \mathrm{~nm}$ diameter were obtained. CNTs were directly drawn and wound (10 layers) onto aluminium frames to produce $70 \times 70 \mathrm{~mm}^{2}$ webs with an aerial density of $0.2 \mathrm{~g} / \mathrm{m}^{2}$. Finally, the CNT webs were stored in a desiccator cabinet (relative humidity $\leq 10 \%$ ) until used.

Amino functionalized CNT webs were produced in a gas-phase reaction following a procedure recently developed and reported. In summary, a 10-layer CNT web is held under static vacuum (-100 kPa) in the presence of $50 \mathrm{mg}$ of ethylenediamine ( $\geq 99.5 \%$; $\mathrm{bp}=118^{\circ} \mathrm{C}$; Sigma-Aldrich). The system was heated to $180^{\circ} \mathrm{C}$ and dwelled for $2 \mathrm{~h}$. This procedure was found to produce a high concentration of chemisorbed (i.e. non-covalently bound) amine without disrupting the delicate highly aligned CNT web and hence is very suitable for studying advanced functionalities as noted above.

\subsection{Specimen preparation}

Composite panels were manufactured according to several different layup patterns depending on the material used and were always symmetric about the mid- (i.e. crack) plane. Thus, from the outer face of the panel to the crack plane, 6 plies of Gurit HMC SE84LV and 3 plies of thin-ply prepreg NTPT or 1 ply of dry thin-ply TeXtreme were used, with the remainder of the layup reflecting symmetry (see Fig. 1). For crack initiation, a polytetrafluoroethylene (PTFE) film (13 $\mu \mathrm{m}$ thick) was included in the crack plane during layup, and, for experiments, a single pristine or amino-treated 10 layer CNT web was also included (Fig 1). The DCB specimens were manufactured as per the ASTM D5528 [5] standard requirements. The CNT webs were laid down in the transverse direction $\left(90^{\circ}\right)$, perpendicular to the fibre and parallel to the crack front. It has been observed that, when placed in parallel to the carbon fibres, CNT web contributes to their interlocking and hence facilitate fibre bridging; in contrast, when the CNT web is placed perpendicularly to the fibre, it inhibits or prevents the interlocking thereby reducing also fibre bridging [7]. It should be noted however that fibre bridging is an artificial toughening mechanism that occurs when testing DCB specimens (since plies at the crack interface are aligned along the $0^{\circ}$ direction) and that in real structures it does not normally occur since delamination tends to originate and propagate between two plies with different orientations. Therefore, laying down the CNT webs transverse to the crack direction ensures that no bridging occurs and allows for a conservative value of the ILFT to be obtained. However, it is recognised that there is an interest in determining the effect of the CNT-web orientation, number of web layers, and layup configuration, and this work is currently being undertaken. 


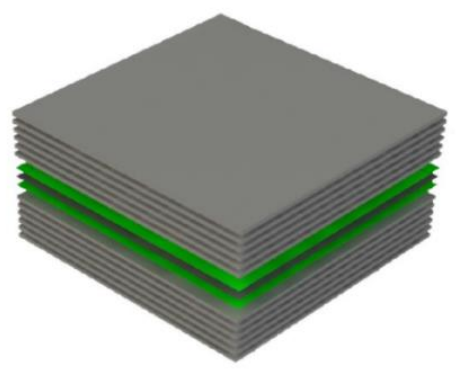

\begin{tabular}{|c|l|}
\hline & 6 ply Gurit HMC SE84LV \\
\hline & $\begin{array}{l}\text { 3 ply NTPT 402 prepreg } \\
\text { or 1 ply TeXtreme dry }\end{array}$ \\
\hline & 10 layer CNT web \\
\hline & $\begin{array}{l}\text { 3 ply NTPT 402 prepreg } \\
\text { or 1 ply TeXtreme dry }\end{array}$ \\
\hline & 6 ply Gurit HMC SE84LV \\
\hline
\end{tabular}

Figure 1: Layup of the specimens investigated.

Preliminary experiments with NTPT 402 prepreg indicated a degradation in ILFT performance in the presence of CNT web, raising the possibility that the 402 resin was failing to penetrate the web effectively. Therefore a set of samples was also prepared using acetone to improve the mobility of the 402 resin and ensure the CNT web was fully wetted and embedded. This methodology has been tested on other, high viscosity, resins and found to be satisfactory. This was not necessary for the SE84LV (ie low viscosity) resin. Thus each 10 layer CNT web was placed dry onto one prepreg panel still on its backing sheet and exposed to an acetone-saturated atmosphere for 1 minute. Absorption of acetone vapour rapidly expanded and diluted the top-most film of resin, causing it to wet and incorporate the CNT web. The panel was removed from the acetone environment and placed under dynamic vacuum for 30 minutes to eliminate the absorbed solvent vapour and the CNT web pre-preg was then incorporated into the layup as usual.

Assembled composite panels were placed on a mould-release treated aluminium tool, covered with a sheet of release film (non-perforated), vacuum bagged and debulked (-1 atm) for $1 \mathrm{~h}$ and finally cured in an autoclave. The recommended cure cycle used is illustrated (Fig 2a). An extended cycle was tested (Fig 2b) to provide more time (45 $\min )$ at the temperature of minimum viscosity $\left(80^{\circ} \mathrm{C}\right)$, and vacuum was maintained throughout in order to facilitate CNT web impregnation.

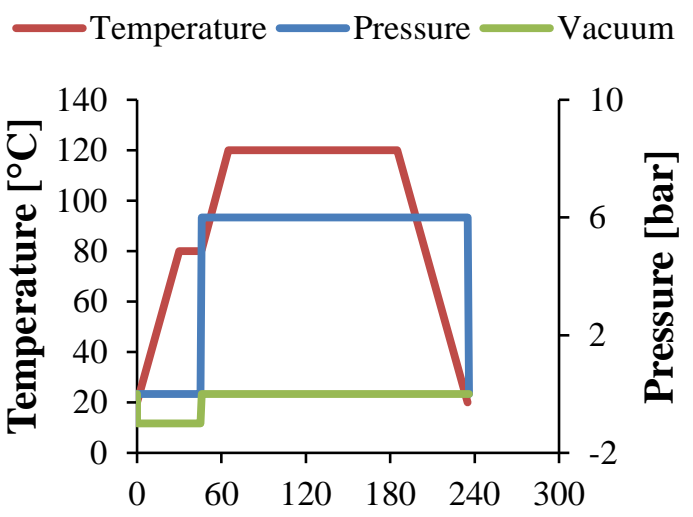

(a)
Time [min]

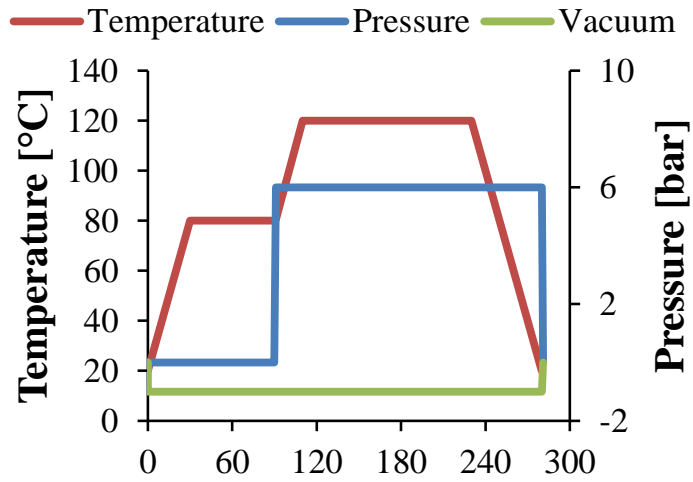

(b)

Time [min]

Figure 2: (a) recommended cure cycle; (b) extended cycle. 
Table 1. Code label used to identify the samples.

\begin{tabular}{lcl} 
Variable & Label & \multicolumn{1}{c}{ Description } \\
\hline \multirow{2}{*}{ Thin ply / Resin } & T & TeXtreme / SE84LV \\
& N & NTPT 402 \\
\hline \multirow{2}{*}{ Process } & R & Recommended cycle (Fig. 2a) \\
& $\mathbf{X}$ & Extended cycle (Fig. 2b) \\
\hline \multirow{3}{*}{ CNT web } & C & Control specimen without CNT web \\
& P & Pristine CNT web \\
& A & Acetone treated pristine CNT web \\
& F & Functionalized CNT web \\
\hline
\end{tabular}

After curing, specimens of nominal thickness $(h) 3.5 \mathrm{~mm}$, length $(L) 130 \mathrm{~mm}$, width $(b) 20 \mathrm{~mm}$, and initial crack length $\left(a_{0}\right) 50 \mathrm{~mm}$ according to the ASTM D5528-13 DCB standard test method [5] (Fig. 3), were cut to size using a diamond saw. Hinges were attached, using a bicomponent epoxy adhesive, to each arm of the specimen and one specimen edge painted with a matt white paint and a graduated scale to allow monitoring of the crack length during the test.

The different configurations of process, treatment and material tested are identified using the code labels presented in Table 1. As an example, NAR indicates specimens with NTPT 402 prepreg and resin at the crack interface with pristine $\mathrm{CNT}$ web treated with $\underline{A}$ cetone to improve resin penetration, and processed by the Recommended cure cycle (Fig 2a). Correspondingly, TFR indicates specimens that in the thin-ply region are made with the TeXtreme fibre and SE84LV resin (from the Gurit prepreg), with Functionalized CNT webs, cured with the Recommended curing cycle.

\subsection{Experiments}

Double Cantilever Beam (DCB) tests were performed to measure the Mode I ILFT [5].

As noted, all specimens have a pre-crack of $50 \mathrm{~mm}$ (the distance between the crack tip and the load introduction point). However this value is affected by the specifics of the manufacturing of the laminate and positioning of the hinges. Using Mohr's analogy, a corrected value of the initial crack length, $a_{0}$, was obtained, as:

$$
a_{0}=\sqrt[3]{\frac{3 \delta_{i} E I}{2 P_{i}}}
$$

where $E$ is the Young's modulus of the laminate (approximated as the Young's modulus of the Gurit laminate since the contribution of the thin plies and CNT webs may be neglected), $I$ is the moment of inertia of one arm, $I=$ $b(h / 2)^{3} / 12$, with $b$ and $h$ the width and the thickness respectively of the sample (Fig. 3). $\delta_{i}$ and $P_{i}$ are the i-th displacement and load, measured during the loading of the laminate prior to crack propagation, and estimated from the initial linear part of the load vs. displacement curve. Tests were conducted on an Instron 5564 universal testing machine equipped with a $2 \mathrm{kN}$ load cell, at a crosshead speed of $1 \mathrm{~mm} / \mathrm{min}$. 


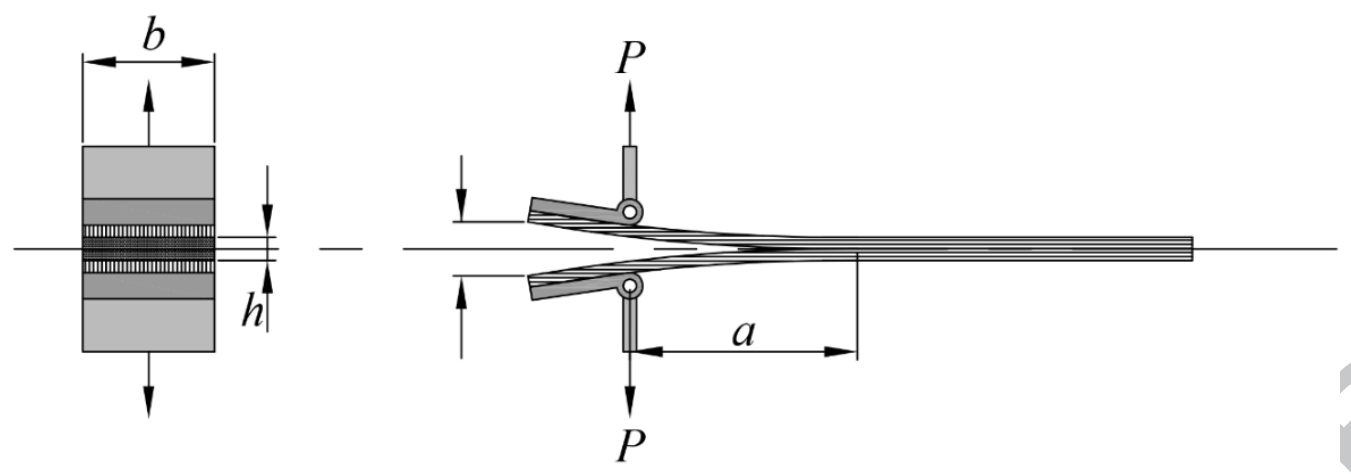

Figure 3: Double Cantilever Beam specimen.

A USB 2.0 Digital Microscope camera synchronized with the universal testing machine, was used to record crack propagation at three second intervals and the images post-analysed. The fracture toughness for the initial and steady state crack propagation, $G_{c}^{i}$ and $G_{c}^{S S}$, respectively, was estimated from Modified Beam Theory:

$$
G_{c}=\frac{3 P \delta F}{2 b(a+|\Delta|)}
$$

where $a$ is the measured crack length, $\Delta$ is the correction coefficient of $a$ and $F$ is the correction coefficient of $\delta$ [5].

\subsection{Post-test analyses}

A Hitachi FlexSEM 1000 Scanning Electron Microscope was used to observe the morphology of the fractured surfaces, and of the cross section of the specimens.

\section{Results and discussion}

\subsection{Effect of CNT webs on NTPT 402 prepreg}

Resistance curves of the calculated interlaminar fracture toughness $\left(G_{c}\right)$ as a function of the crack length $(\Delta a)$, for the NTPT 402 thin-ply specimens with pristine CNT webs and recommended processing exhibit (Fig. 4) a reduction in respectively the fracture initiation $\left(G_{c}^{i}\right)$ and steady state $\left(G_{c}^{S S}\right)$ values of $44 \%$ and $68 \%$. 


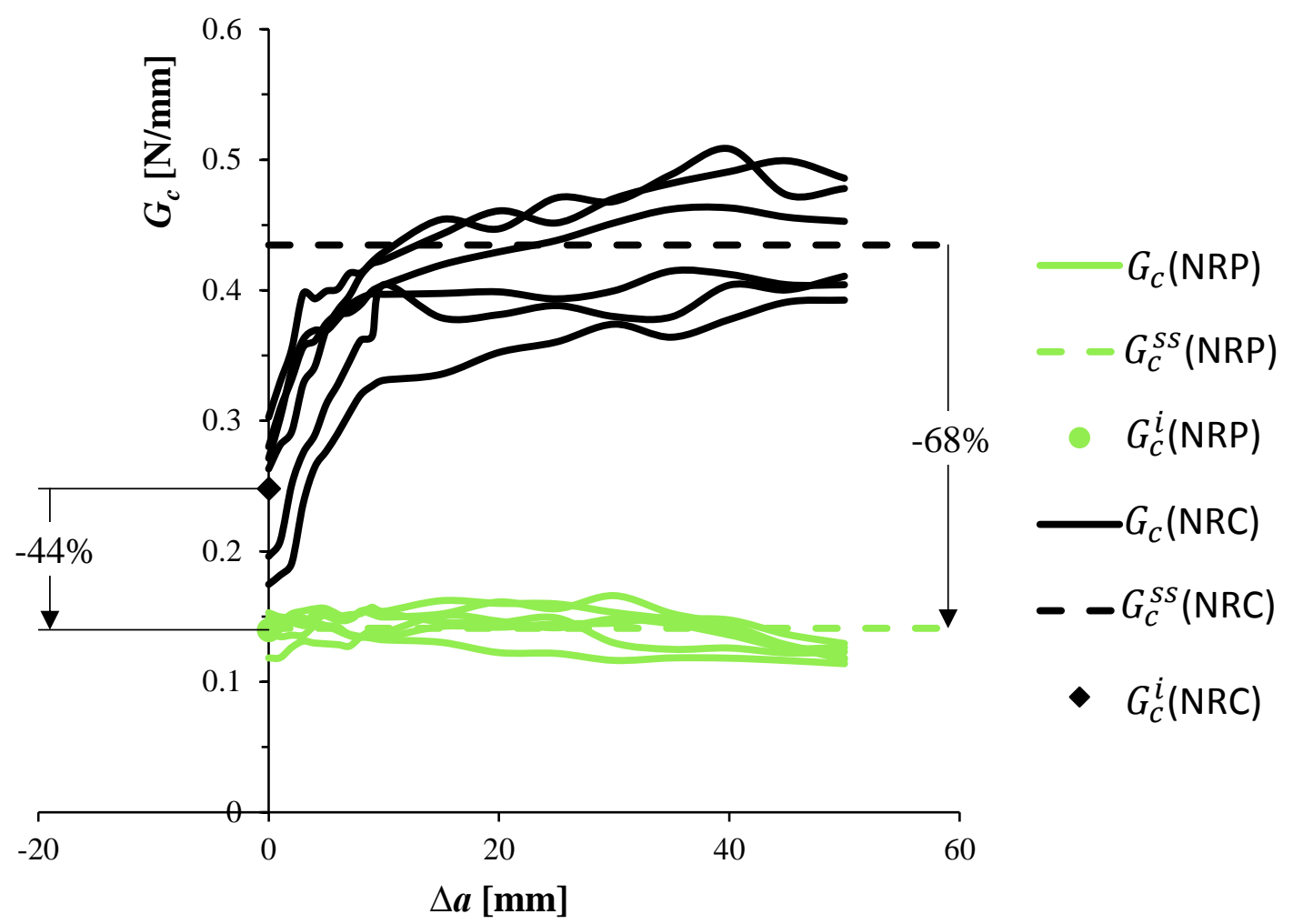

Figure 4: Resistance curves $G_{c}(\Delta a)$ of the NRP and NRC samples.

The interlaminar fracture toughness when a CNT web is incorporated has been reported previously by Bhanushali and Bradford [6] to vary significantly and both positively and negatively with the number of web layers used and their orientation in Glass FRP. A dramatic effect on ILFT was recently reported by Chitwan et al [7] who observed a 65\% decline when using the aerospace grade toughened epoxy 977-2 from Solvay, and was independent of the amount of webs used.

In order to ensure that the loss in fracture toughness was not a result of failure to fully embed the nanotubes in the resin, the curing cycle of the composite was modified to extend the period of low viscosity (Figure 2b, samples NXP) or else to temporarily reduce the viscosity of the surface resin using acetone vapour (samples NRA).

All configurations showed a reduction of $44 \%$ and $67 \%$ for the initiation and steady state value of the interlaminar fracture toughness, respectively (Fig. 5). No change was noted for the different sample types tested, indicating that the solvent treatment itself is not deleterious, and that poor contact of the resin with the CNT web is not the cause of the degradation in performance. This result was further confirmed by similarity of the SEM images of untreated (NRP) and treated (NXP, NRA) samples which showed no substantial difference as a result of these treatments. 


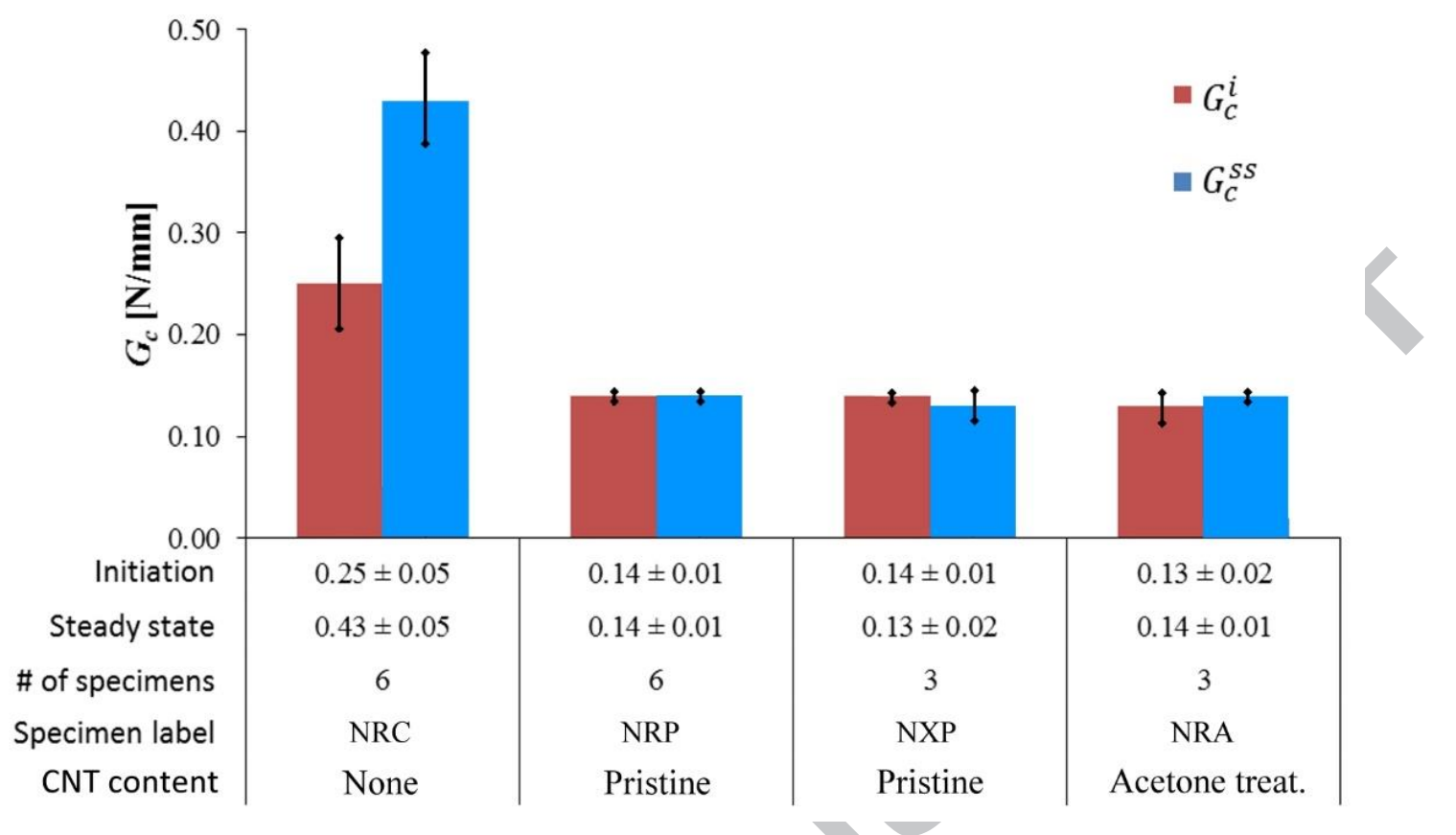

Figure 5: Summary of the experimental results obtained for the NTPT 402 thin-ply prepreg.

The dominant cause of weakening for the Solvay 977-2 resin in the presence of CNT web was identified by Chitwan et al [7] as the poor interfacial strength between the CNTs and the particular epoxy formulation. The precise nature of this interface failure was not clarified, however it is evident that in NTPT 402, another example of interface failure is observed. The planar web morphology and nano-scale size and spacing of the CNTs ensures an effectively uninterrupted fracture plane through the material, as seen in the SEM of the fracture surfaces (Fig. 6), where the scalloped morphology (as observed in Fig. 6(a)) is largely or completely eliminated by the planar structure of the CNT-web (Fig. 6(b-d)).
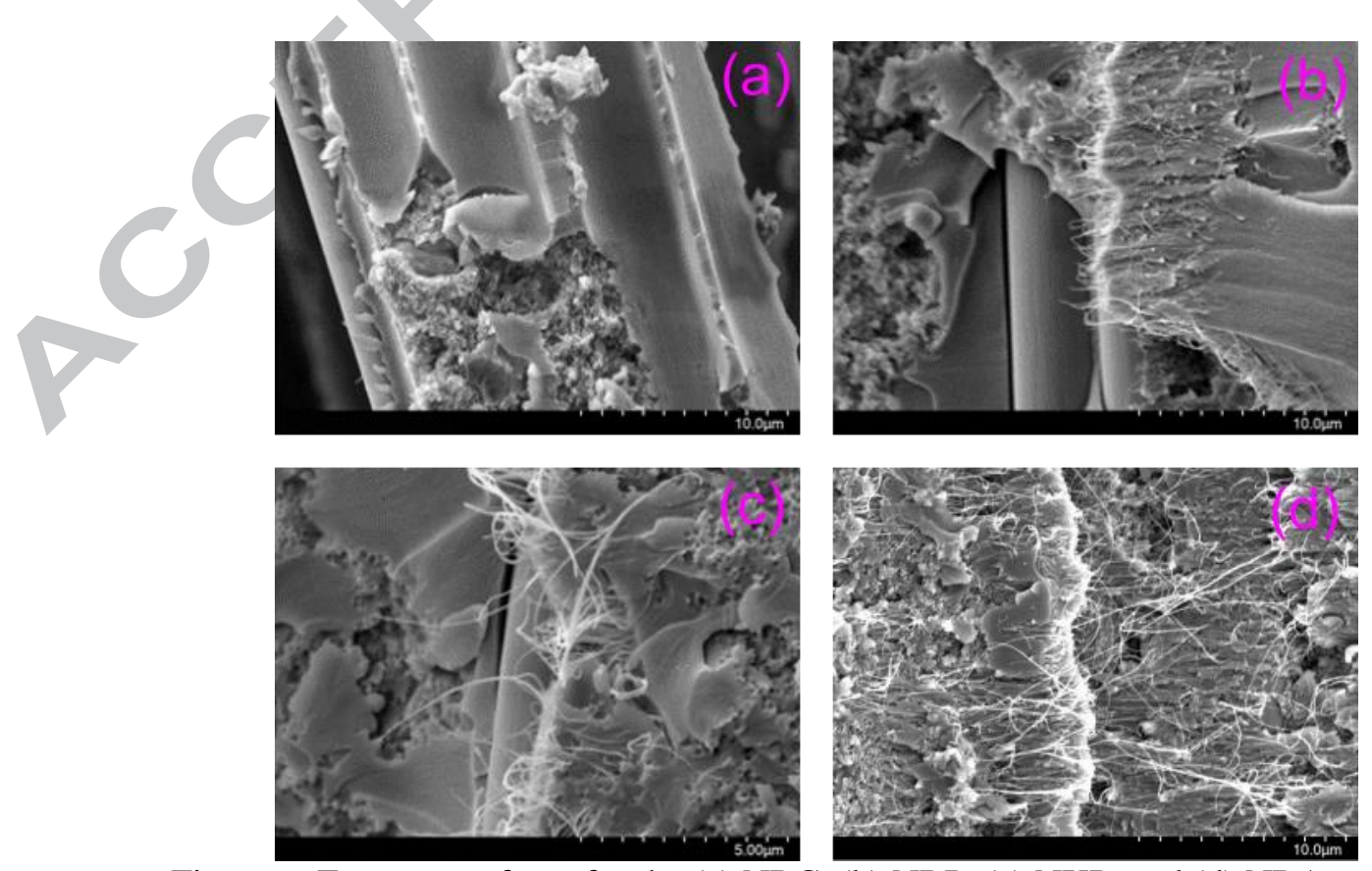

Figure 6: Fracture surfaces for the (a) NRC, (b) NRP, (c) NXP, and (d) NRA samples. 


\subsection{Effect of CNT webs on TeXtreme/SE84LV}

Previous investigations have shown good compatibility between CNT web and the SE84LV resin from Gurit [7], so this was chosen in combination with the dry thin plies provided by TexTreme in order to assess the thin-ply effect, in comparison to conventional laminates [7-9]. Control samples (TRC, i.e. without CNT web), and samples with functionalized and pristine CNT web (TRF, TRP, respectively) were processed using the recommended conditions (Fig. 2a). As noted previously, the $90^{\circ}$ oriented CNT web should provide the lowest fracture toughness since it might be anticipated to inhibit the development of bridging in the interlaminar region (this condition, therefore should be seen as the worst case scenario).

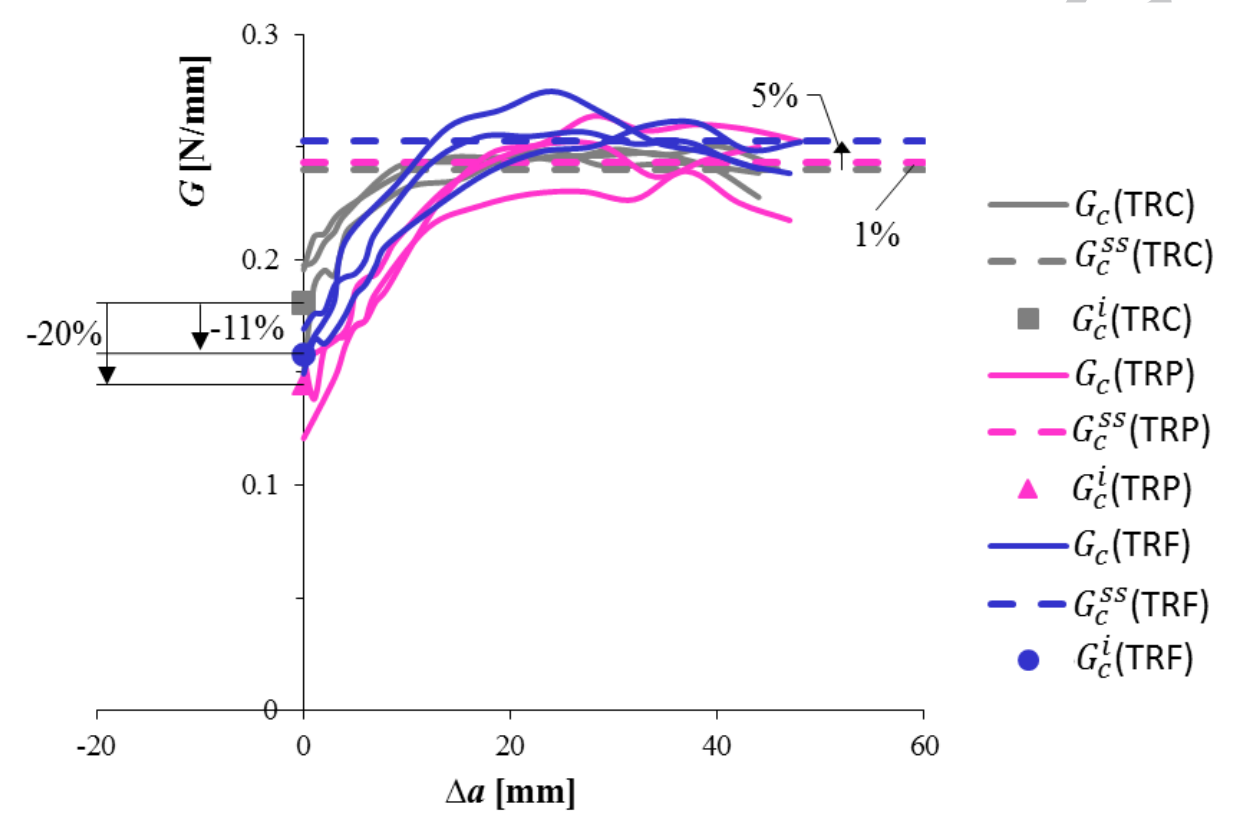

Figure 7: Resistance curves $G_{c}(\Delta a)$ of the TRC, TRP, and TRF samples.

The presence of CNT webs caused a minor decrease in the initiation (Fig. 7, 20\% for TRF and $11 \%$ for TRP), but the steady state fracture propagation toughness was largely unaffected (Fig. 8). 


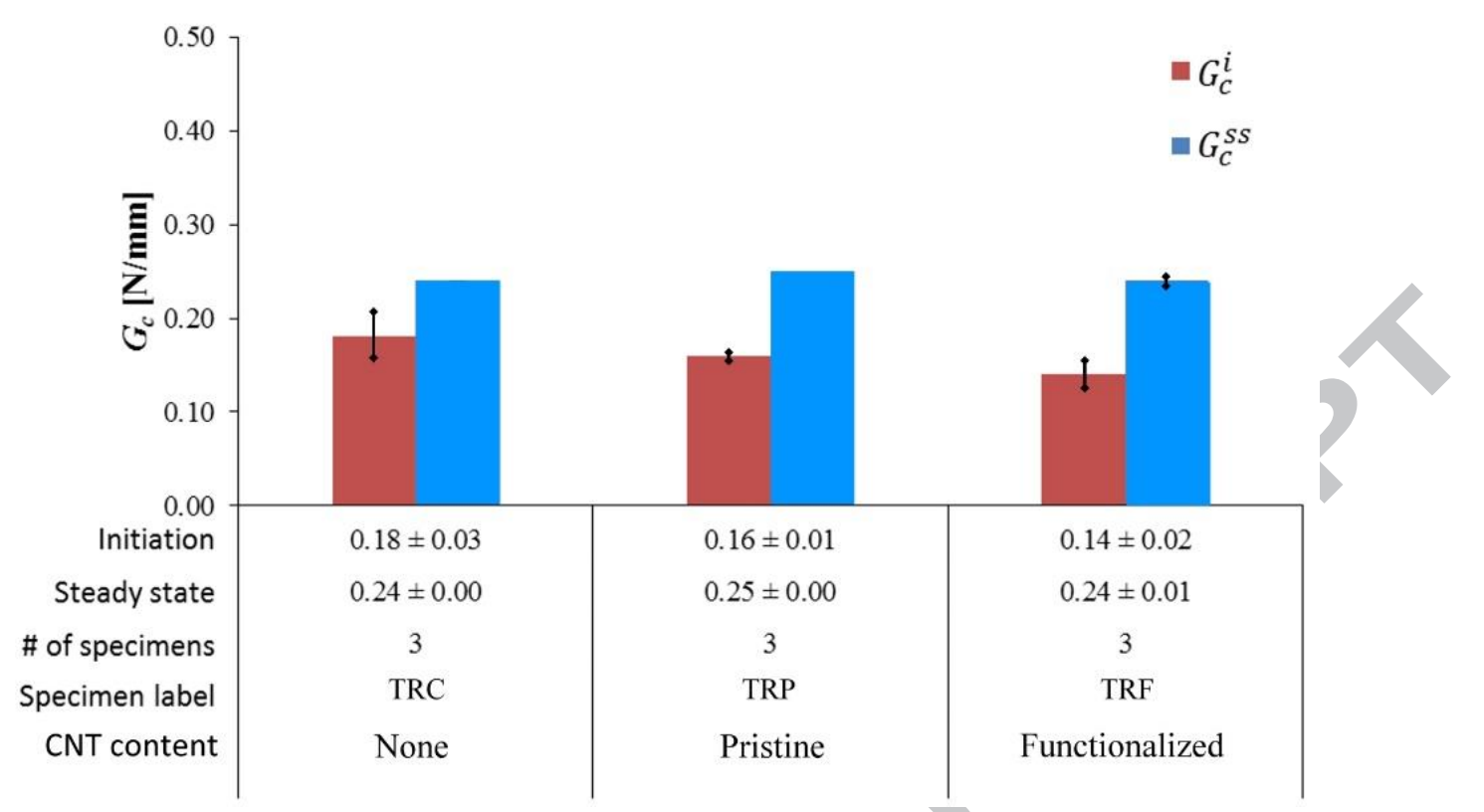

Figure 8: Summary of the results obtained for the TeXtreme/SE84LV.

From a comparison of the control specimens, NRC and TRC, the ILFT of the latter is substantially lower. This is reflected in the different fracture morphology, with the TRC (Fig. 9(a)) showing a smoother fracture surface and evidently poorer CF/resin interaction than the NRC (Fig. 6(a)). The NTPT 402 and the SE84LV are different toughened resins, for which limited data is available, therefore limiting the interpretation of the fracture behaviour.

The fracture toughness of the NTPT specimens containing CNT-web is substantially lower than the control specimens and this is attributed to a poor resin/CNT interfacial strength and the planar web morphology. A similar fracture behaviour was previously reported for the Solvay 977-2 toughened resin [7]. The roughness of the NRC specimens (Fig. 6(a)) arises from matrix fracture and carbon fibre-matrix debonding, and so the fracture surfaces exhibit a fibrescale characteristic size. The planar CNT-web, by having a weak resin interfacial strength, promotes the onset and propagation of a planar crack through the structure of the web. The fracture morphology therefore reflects the scale and structure of the CNT-web. Although the CNT modified specimens appear rougher (Fig. 6(b-d)), the roughness is of a finer scale than observed for the control specimens (Fig. 6(a)).

The lack of negative effect due to the insertion of CNT-web into the SE84LV resin indicates the resin/CNT interfacial strength is at least as strong as the bulk resin and perhaps also the carbon fibre/resin interface. As observed in Fig. 9(b), the fracture plane crosses, but does not substantially follow, the CNT-web plane. As a result, the macroscopic fracture morphology of the control (Fig. 9(a)) and CNT-web modified (Fig. 9(b)) specimens is similar. 

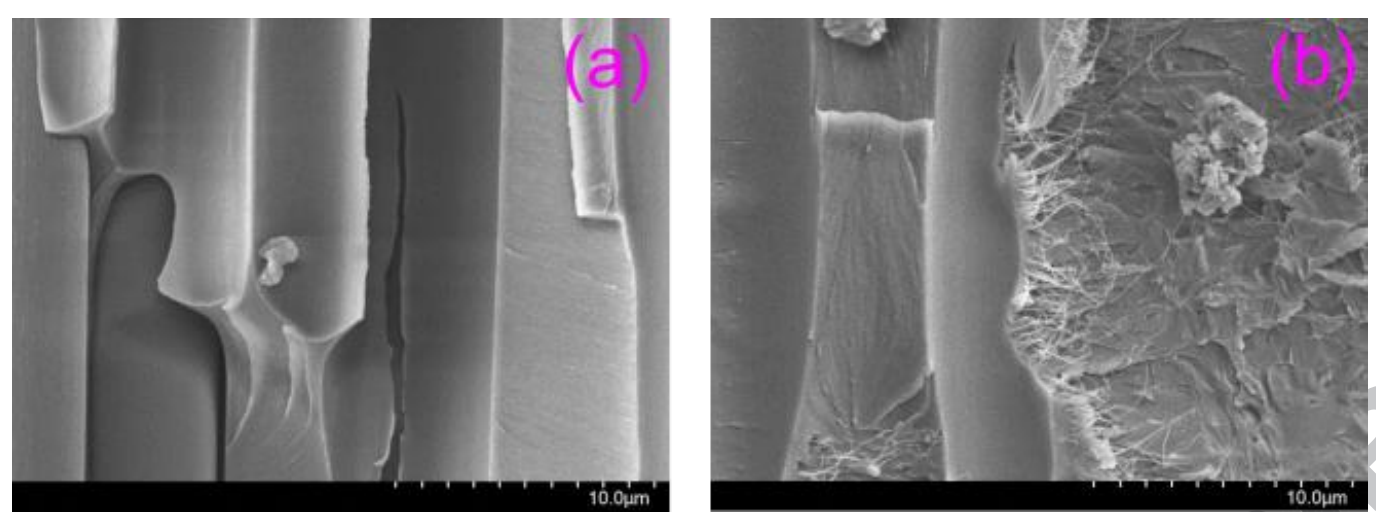

Figure 9: Fracture surfaces for the (a) TRC and (b) TRP samples.

\subsection{Discussion}

The experimental results obtained for the NTPT 402 resin clearly show that an incompatibility exists between CNT web and the NTPT 402 resin, as was previously observed for the Solvay 977-2 resin [7]. This effect is not intrinsic to CNT web but rather to the particular resin formulation. Scope exists to modify the CNT web, for example by amino-functionalization, to overcome this detriment, indeed it is essential to understand the fundamental causes of this effect.

For the TeXtreme/SE84LV specimens, experimental results obtained in a previous investigation have measured a steady state value of the interlaminar fracture toughness of $0.35 \mathrm{~N} / \mathrm{mm}$ for conventional laminates [7]. Pristine thinplies tested in this investigation showed a steady state value of the interlaminar fracture toughness of $0.24 \mathrm{~N} / \mathrm{mm}$, $31 \%$ lower than reported for the conventional laminate. The reduction in interlaminar fracture toughness with decreasing ply thickness is expected (because decreasing the ply thickness decreases the waviness of the fibre and therefore the bridging), and has been reported in other investigations [15]. The introduction of pristine CNT web for this thin-ply material system does not cause any reduction in the interlaminar fracture toughness. This demonstrates that the CNT web can be utilised as an interfacing 'nano-ply' within the thin-ply design to improve thermoelectric properties without degrading structural properties. It should be highlighted that, in the case of thin-ply laminates, the number of possible interfaces increases, and consequently the quantity of CNT webs that could be embedded in the laminate.

Finally, it should be observed that the use of functionalized CNT webs for this case does not produce a toughening effect such as has been found for conventional laminates [8]. The Gurit HMC SE84LV system has a small though clear excess of resin which, when combined with amine-treated CNT web alone, is ample to interact with the crosslinker to enhance the CNT-resin interaction. However, the inclusion of the dry thin ply plus the CNT web is thought sufficient to exhaust this excess and limit the extent of any cross-linking interaction. The other effect that is thought to be relevant is that the amine is only chemisorbed onto the CNT surface and the temperature at which it reacts with the SE84LV resin in the range of only 40 to $90{ }^{\circ} \mathrm{C}$ [8]. Insertion of the functionalized web in direct contact with the SE84LV would capture the amine. However insertion between dry thin ply, which depends on heating and vacuum to move the SE84LV resin into it and the included CNT web, would result in significant diffusion and reaction of the 
amine away from the CNT surface and hence loss of effect. This should be remedied by the use of a Thin-Ply prepreg bearing a compatible resin such as SE84LV.

\section{Conclusions}

Experiments were conducted on two different thin-ply material systems with the aim of assessing the effect that the introduction of embedded CNT web has on the mode I interlaminar fracture toughness. Experiments have shown that the introduction of CNT webs results in a decrease in ILFT for the NTPT 402 prepreg of about $44 \%$ and $68 \%$, for the initial and steady state values, respectively. This degradation of performance is attributable to an incompatibility between the CNT web and the particular resin formulation. Scope exists to improve the performance of CNT web, for example by amino-functionalization. Indeed it is essential to understand the fundamental causes of this effect if the potential offered by CNTs and other nanomaterials to improve the physical and electro-thermal properties of modern composites is to be realized. In contrast, no depreciation of the interlaminar fracture toughness was observed for the SE84LV specimens. This result is particularly important because it demonstrates hierarchical thin-ply/CNT web structures can be obtained without compromising their structural performance.

\section{Acknowledgements}

The authors would like to acknowledge the financial support from the EPSRC project MACANTAMultifunctional hierarchical advanced composite aerostructures utilising the combined properties of di erent carbon nanotube (CNT) assemblies (EP/N007190/1). The first and third authors would also like to acknowledge Prof. Giuseppe Pitarresi of the University of Palermo, and the financial support provided by the Collegio Universitario ARCES through the Erasmus+ mobility grant.

\section{Data availability}

Datasets related to this article may be found at http://dx.doi.org/10.17632/pfr55wdn72.1, an open source online data repository hosted at Mendeley Data.

\section{References}

[1] Yao X, Falzon BG, Hawkins SC, Tsantzalis S. Aligned carbon nanotube webs embedded in a composite laminate: A route towards a highly tunable electro-thermal system. Carbon N Y 2018;129:486-94. doi:10.1016/j.carbon.2017.12.045.

[2] Yao X, Hawkins SC, Falzon BG. An advanced anti-icing/de-icing system utilizing highly aligned carbon nanotube webs. Carbon N Y 2018;136:130-8. doi:10.1016/j.carbon.2018.04.039.

[3] Yao X, Falzon BG, Hawkins SC. Orthotropic electro-thermal behaviour of highly-aligned carbon nanotube web based composites. Compos Sci Technol 2019;170:157-64. doi:10.1016/J.COMPSCITECH.2018.11.042.

[4] Hawkins SC, Poole JM, Huynh CP. Catalyst Distribution and Carbon Nanotube Morphology in Multilayer Forests by Mixed CVD Processes. J Phys Chem C 2009;113:12976-82. doi:10.1021/jp810072j.

[5] ASTM D5528 - 13: Standard Test Method for Mode I Interlaminar Fracture Toughness of Unidirectional FiberReinforced Polymer Matrix Composites. 2013. doi:10.1520/D5528.

[6] Bhanushali H, Bradford PD. Woven Glass Fiber Composites with Aligned Carbon Nanotube Sheet Interlayers. J 
Nanomater 2016;2016:1-9. doi:10.1155/2016/9705257.

[7] Chitwan R, Nistal A, Falzon BG, Hawkins SC. Mode I interlaminar fracture toughness of carbon nanotube webmodified polymer composites. 21st Int. Conf. Compos. Mater. Xi'an, 20-25th August 2017, 2017.

[8] Nistal A, Chitwan R, Falzon BG, Hawkins SC. Amino functionalisation of carbon nanotube webs for achieving high structural performance of multifunctional nano-enhanced hierarchical composites. 21st Int. Conf. Compos. Mater. Xi'an, 2017.

[9] Nistal A, Falzon BG, Hawkins SC, Chitwan R, García-Diego C, Rubio F. Enhancing the fracture toughness of hierarchical composites through amino-functionalised carbon nanotube webs. Compos Part B Eng 2019;165:537-44. doi:10.1016/J.COMPOSITESB.2019.02.001.

[10] Russello M, Diamanti EK, Catalanotti G, Ohlsson F, Hawkins SC, Falzon BG. Enhancing the electrical conductivity of carbon fibre thin-ply laminates with directly grown aligned carbon nanotubes. Compos Struct 2018;206:272-8. doi:10.1016/j.compstruct.2018.08.040.

[11] Amacher R, Cugnoni J, Botsis J, Sorensen L, Smith W, Dransfeld C. Thin ply composites: Experimental characterization and modeling of size-effects. Compos Sci Technol 2014;101:121-32. doi:10.1016/J.COMPSCITECH.2014.06.027.

[12] Arteiro A, Catalanotti G, Xavier J, Camanho PP. Notched response of non-crimp fabric thin-ply laminates. Compos Sci Technol 2013;79:97-114. doi:10.1016/J.COMPSCITECH.2013.02.001.

[13] Yokozeki T, Aoki Y, Ogasawara T. Experimental characterization of strength and damage resistance properties of thinply carbon fiber/toughened epoxy laminates. Compos Struct 2008;82:382-9. doi:10.1016/J.COMPSTRUCT.2007.01.015.

[14] Sihn S, Kim RY, Kawabe K, Tsai SW. Experimental studies of thin-ply laminated composites. Compos Sci Technol 2007;67:996-1008. doi:10.1016/J.COMPSCITECH.2006.06.008.

[15] Frossard G, Cugnoni J, Gmür T, Botsis J. Mode I interlaminar fracture of carbon epoxy laminates: Effects of ply thickness. Compos Part A Appl Sci Manuf 2016;91:1-8. doi:10.1016/J.COMPOSITESA.2016.09.009.

[16] Guillamet G, Turon A, Costa J, Renart J, Linde P, Mayugo JA. Damage occurrence at edges of non-crimp-fabric thinply laminates under off-axis uniaxial loading. Compos Sci Technol 2014;98:44-50. doi:10.1016/J.COMPSCITECH.2014.04.014.

[17] Huynh CP, Hawkins SC. Understanding the synthesis of directly spinnable carbon nanotube forests. Carbon N Y 2010;48:1105-15. doi:10.1016/J.CARBON.2009.11.032. 